\title{
Acute Monoplegia Due to Spinal Injury
}

\author{
Gyani Jail Singh Birua' \\ ${ }^{1}$ Department of Neurosurgery, Central Referral Hospital/Sikkim \\ Manipal Institute of Medical Sciences, 5th Mile, Tadong, Gangtok, \\ Sikkim, India

\begin{abstract}
Address for correspondence Gyani Jail Singh Birua, MBBS, MCh (Neurosurgery), Staff Qr. B-102, CRH/SMIMS Campus, 5th Mile, Tadong, Gangtok, Sikkim 737102, India (e-mail: drgjsbirua@gmail.com).
\end{abstract}
Abstract
Keywords
- monoplegia
- spinal trauma
- corticospinal tract injury

Monoplegia due to spinal cord infarction, spinal epidural anesthesia, and epidural blood patch have been reported. Monoplegia due to cervical cord injuries is rare, and monoplegia of upper extremity is even rarer. The authors present a case of a 33-yearold woman, who fell from a two-storey building and developed monoplegia of right upper extremity. Magnetic resonance imaging of the cervical spine reveals long-segment $\mathrm{T} 2 \mathrm{~W}$ hyperintensity $(\mathrm{C} 3-\mathrm{C} 7)$ with involvement of the right hemicord at $\mathrm{C} 4-\mathrm{C} 5$ level.

\section{Introduction}

Traumatic spinal injury (TSI; injury to the spinal column, spinal cord, or both) commonly leads to significant impairment in quality of life. ${ }^{1}$ Internationally, most injuries are caused by road traffic accidents (RTAs), with both low and high falls.,3, Spinal cord injury presents with varying grades of motor and sensory dysfunction (hemiplegia, paraplegia, or quadriplegia) below the involved segment of the spinal cord. Rare cases of monoplegia due to spinal cord infarction,,${ }^{4,5}$ spinal epidural anesthesia, ${ }^{6,7}$ and epidural blood patch ${ }^{8}$ have been reported. Incidences of monoplegia due to traumatic spine injuries are rare, and isolated monoplegia of upper extremity is even rarer. This case report might be the first traumatic cervical spine injury presented as isolated upper extremity monoplegia.

We present a case of a 33-year-old woman, who fell from a two-storey building and developed monoplegia of the right upper extremity.

\section{Case Presentation}

A 33-year-old woman (tourist) fell from a two-storey building while taking a selfie into the nearby drainage canal. She immediately developed severe pain over back of the neck and monoplegia as well as severe pain of the right upper extremity. She developed mild weakness of the left upper extremity as well. She was rescued by passersby and moved to the nearest primary health center, from where she was referred to us for specialist care.

The patient was of average build and height. She was in painful distress and had multiple deep lacerated wounds over the head. She also had extreme tenderness over back of the neck, arm of left extremity, and whole right extremity. Power of the right upper extremity was $0 / 5$ in all groups of muscles, while in the left upper extremity it was 4/5 at the shoulder and elbow joints with weak hand grip. Power in the bilateral lower extremity was 5/5 with intact bladder and bowel functions.

\section{Investigations}

Noncontrast computed tomographic (CT) scan of the brain and cervical spine was normal ( $\mathbf{- F i g . 1} \mathbf{1}$ ). X-ray of the chest suggested bilateral fracture of the first rib. Initially, clinical diagnosis was brachial plexus injury, but magnetic resonance imaging (MRI) revealed intact brachial plexus. MRI of the cervical spine was advised, which revealed long-segment T2W hyperintensity (C3-C7) with involvement of the right hemicord at C4-C5 level. Posterior disc protrusion was also seen at C3-4, C4-5, C5-6, and C6-7 spinal cord level (-Fig. 2).

\section{Management}

The patient was managed conservatively in intensive care unit (ICU) with cervical collar, steroids, and other supportive measures. By the third day of admission, power of the left upper extremity improved, but she developed difficulty in breathing and required $\mathrm{O}_{2}$ to maintain normal oxygen saturation. By seventh day pain in bilateral upper limbs subsided, breathing improved, but power in the right upper extremity remained the same as at the time of presentation (power: 0/5).

\section{received}

July 6, 2018

accepted

September 6, 2018

published online

August 27, 2019
DOI https://doi.org/

10.1055/s-0039-1694851 ISSN 2277-954X.
(C2019 Neurological Surgeons' Society of India
License terms

(이 (1) $\Theta \circledast$ 


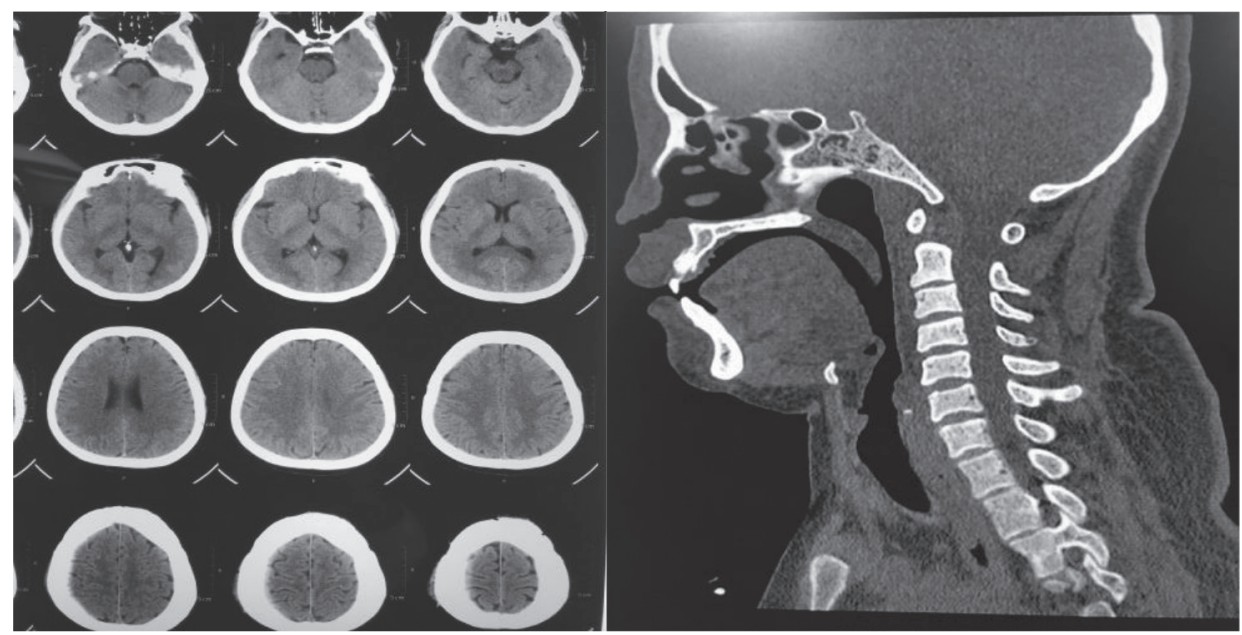

Fig. 1 Normal noncontrast CT scan of the brain and cervical spine.
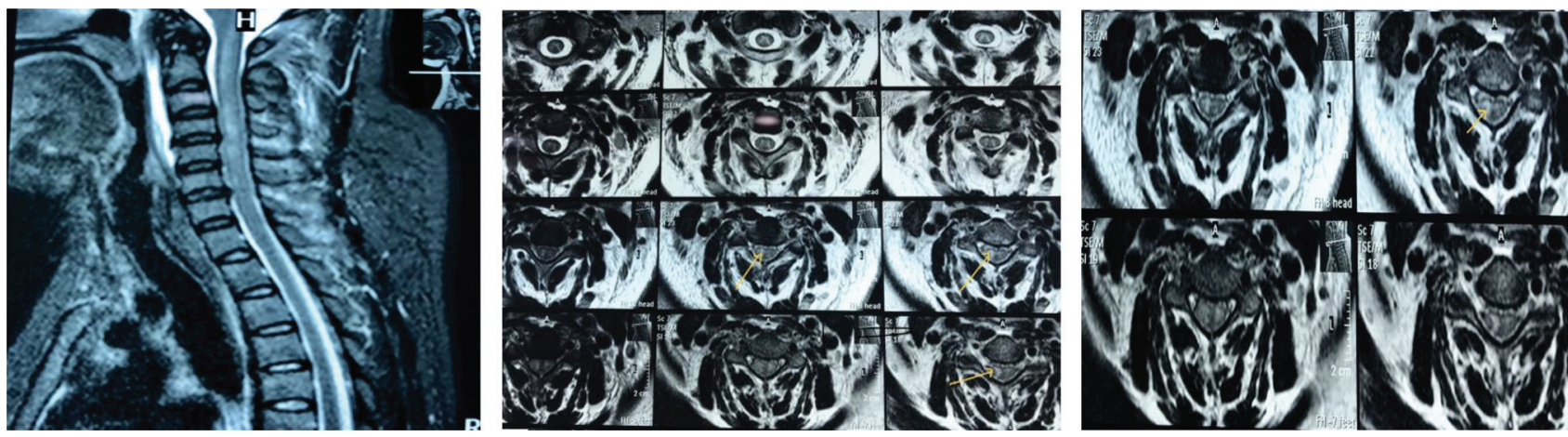

Fig. 2 MRI of cervical spine showing long-segment (C3-C7) T2W hyperintensity with involvement of the right hemicord at C4-C5 level (yellow arrows). Posterior disc protrusion was also seen at C3-4, C4-5, C5-6, and C6-7.

\section{Outcome and Follow-up}

After 2 weeks of hospitalization, the patient was able to move the fingers of right upper extremity (power: $1 / 5$ ). At 2 months follow-up, she was noted to have $3+/ 5$ right shoulder flexion and extension, right elbow flexion was $3+/ 5$, and extension was $3 / 5$. Handgrip had also improved up to some extent.

\section{Conclusion}

As the fibers of corticospinal tract cross the midline in the cervical spinal tract, lower limb fibers are placed more laterally, and upper limb fibers are placed more medially at the cervical level. Arrangements of fibers from medial to lateral are cervical, thoracic, lumber, and sacral (CTLS) at the cervical region. In (-Fig. 2) it can be seen that "comma"-shaped spinal hemorrhagic contusion has involved the cervical fibers and probably some thoracic fibers in medial part of right hemicord, sparing the rest of the corticospinal tract fibers and whole spinothalamic tract. This can explain monoplegia of the right upper extremity and slight difficulty in breathing, with preservation of sensation in both the upper limbs.
Hence it can be said that in case of upper extremity monoplegia due to trauma, isolated spinal motor tract injury should also be considered as differential diagnosis along with brachial plexus injury.

\section{Source(s) of Support}

None.

\section{Presentation at a Meeting}

None.

\section{Conflicts of Interest}

None.

\section{References}

1 Bouyer B, Vassal M, Zairi F, et al. Surgery in vertebral fracture: epidemiology and functional and radiological results in a prospective series of 518 patients at 1 year's follow-up. Orthop Traumatol Surg Res 2015;101(1):11-15

2 Wang H, Zhang Y, Xiang Q et al. Epidemiology of traumatic spinal fractures: experience from medical university-affiliated hospitals in Chongqing, China, 2001-2010. J Neurosurg Spine 2012;17(5):459-468

3 Leucht P, Fischer K, Muhr G, Mueller EJ. Epidemiology of traumatic spine fractures. Injury 2009;40(2):166-172 
4 Nelson JA, Ho CY, Golomb MR. Spinal cord stroke presenting with acute monoplegia in a 17-year-old tennis player. Pediatr Neurol 2016;56:76-79

5 Harlander M, Bajrović FF, Blinc A, Sabovic M. Monoparesis due to spinal cord infarction associated with thoracoabdominal aneurysm. Heart Vessels 2008;23(5):359-362

6 Balaban O, Gürkan Y, Kuş A, Toker K, Solak M. Monoplegia after combined spinal epidural anesthesia. Agri 2013;25(4):183-186
7 Epstein NE. Neurological complications of lumbar and cervical dural punctures with a focus on epidural injections. Surg Neurol Int 2017;8:60

8 Cheung AH, Li LF, So VC, Leung MK, Lui WM. Transient monoplegia and paraesthesia after an epidural blood patch for a spinal cerebrospinal fluid leak. J Clin Neurosci 2015;22(9):1493-1495 